\title{
Identifying the Factors that Control Rockburst Damage to Underground Excavations
}

\author{
J. Albrecht School of Civil and Resource Engineering, The University of Western Australia \\ Y. Potvin Australian Centre for Geomechanics, Western Australia
}

Rockburst damage in mines has a significant impact on mine productivity, infrastructure and workers safety. The severity of damage ranges from shakedown of loose material, localised support failure to complete failure of the installed support and collapse of an excavation. At all scales of rockburst damage there is a risk of serious injury and fatalities to mine personal. The costs associated with managing rockburst damage are often significant; with damage sites requiring rehabilitation, redesign, infrastructure repair and replacement. In some cases mines are required to make significant changes to the mining methods, often requiring disruption to operations and possible closure.

In terms of rockburst research, little has been done to identify factors that control the stability of an excavation boundary submitted to seismic loads. This lack of research is evident in the absence of reliable design guidelines and methods to evaluate the performance of excavations in rockbursting ground.

This paper outlines a methodology that identifies the factors that control the stability of underground excavations in rockbursting conditions. A modelling approach is developed which identifies significant parameters and develops criteria that can be used by mine personnel to evaluate the rockburst potential of the underground workings. The methodology also provides a useful template for the systematic and detailed reporting of rockburst damage sites. The work is based on data collected from rockburst damage sites at three Western Australian mines.

\section{INTRODUCTION}

A method is developed that identifies the factors that control the stability of underground excavations submitted to seismic loads. These factors are combined to form mine specific empirical models that are used to predict the location of rockburst damage at mines.

At present there are few tools available to evaluate the location of potential rockburst damage in mines. The models (Bieniawski, 1989; Gill et al., 1993; Grimstad and Barton, 1993; Kaiser et al., 1992; Laubscher, 1977; Potvin, 1988) that do exist have not been well calibrated to actual observations of rockburst damage. Where this method deviates from existing techniques is that the model is developed using parameters empirically calibrated to observations of rockburst damage. The model approach allows mine personnel to assess the rockburst potential of existing excavations and identify site-specific parameters that contribute to the location of rockburst damage. In addition the conceptual model parameters provide mine personnel with a detailed reporting template that allows the systematic and standardised reporting of rockburst damage at mines. The quantitative description of the model parameters also removes the potential error associated with subjective classification schemes.

\section{GENERAL DESCRIPTION OF THE CONCEPTUAL ROCKBURST DAMAGE MODEL}

A conceptual model is developed to define each of the factors that may contribute to the location of rockburst damage in mines. The conceptual model describes the rockburst damage potential of an excavation in terms of following two general factors.

- The Dynamic load at the excavation boundary, and

- The Excavation condition.
The Dynamic load describes the amplitude and frequency of ground motion at the boundary of the excavation.

The Excavation Condition describes the stability of the excavation prior to dynamic loading. The factor is described in terms of the following parameters.

- Excavation location

- The boundary stress state

- The rockmass strength

- Excavation geometry

- Structural orientation relative to excavation surfaces

- The rockmass type and character of discontinuities

- Rockmass fatigue around the boundary of the excavation

- Excavation stiffness

- Support Capacity

\section{SUMMARY OF MODELLING APPROACH}

The model parameters are evaluated at node positions, evenly spaced along the centreline of each drive section. Each node represents a unique section of drive. For a given seismic event, the parameters describing the dynamic load and the condition of the excavation are assigned to each node. Figure 1 illustrates an example of nodal positions along a drive centreline.

The model parameters of the damage sites and nondamaged sites are compared using frequency distribution plots. These plots are used to develop criteria separating the rockburst and non-damaged drive locations. Each of the model parameters is ranked in terms of how well the criteria separates rockburst damage from non-damaged areas. The analysis is also conducted using combinations of the model parameters to identify the optimal combination of criteria to predict rockburst damage. 


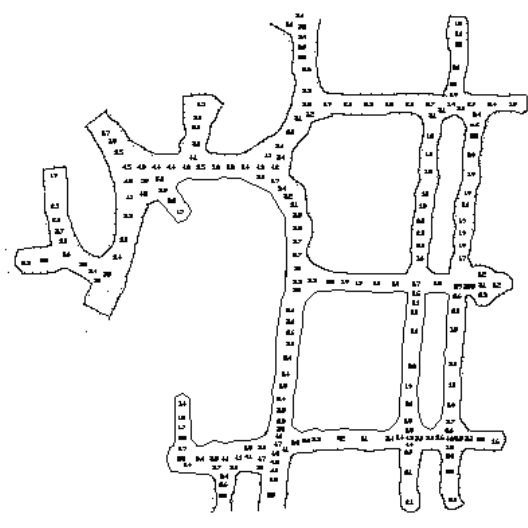

FIG. 1 Plan view of a development level showing the positions of model nodes along the drive centreline

To evaluate the success of different combinations of model parameters, the location of actual damage is compared to the location of damage indicated by the model criteria.

The damage criteria established in the model is then applied to the population of non-damaging seismic events to assess the reliability of the model criteria in identifying non-damaged nodes.

Common parameters that are identified as good separators of rockburst damage are combined to form a specific mine model to evaluate the resistance of underground excavations to rockburst damage.

\section{MODEL PARAMETERS}

A number of assumptions have been made in order to simplify the calculation of the model parameters. These assumptions are not expected to adversely affect the reliability of the modelling approach, providing the techniques used to calculate the parameters adequately account for the relative variations between model parameters at damaged and non-damaged sites. The calibration of the model parameters to actual observations of rockburst damage also reduces the sensitivity of the model to calculation errors resulting from the way a model parameter is quantified. It is unlikely that more complicated techniques to quantify the model parameters would provide any more level of accuracy using the empirical modelling approach adopted in this paper.

\subsection{Dynamic Load Parameters}

The following parameters were identified from the literature as potentially contributing to rockburst damage in mines.

- The peak amplitude of ground motion at the excavation boundary

- The wavelength or frequency of the incident seismic wave relative to excavation dimensions.

\subsubsection{The peak ground motion at the excavation boundary}

A seismic source model is applied to characterise the ground motion amplitude with distance from the seismic source. As the majority of empirical ground motion relationships are expressed in terms of the peak particle velocity (ppv), peak ground motions in the model are expressed in terms of velocity (Kaiser et al., 1995; McGarr, 1991; McGarr et al., 1981; Spottiswoode, 1984; Spottiswoode and McGarr, 1975). Criteria defining rockmass damage and the capacity of support systems have also been described in terms of peak particle velocities (Dowding and Rozen, 1978; St John and Zahrah, 1987; Stacey and Ortlepp, 2000).
In the case were ground motions are recorded using accelerometers; Equation 1 is used to calculate ppv using the peak particle acceleration (ppa) and corner frequency $\left(f_{c}\right)$.

$$
p p v=\frac{p p a}{2 \pi f_{c}}
$$

The seismic source model used in this study assumes a constant near field peak particle velocity $\left(\mathrm{ppv}_{\mathrm{nf}}\right)$ within the seismic source region. Outside the source, the ground motion amplitudes attenuate with distance from the source. Similar models have been used by researchers to describe ground motion amplitudes in the near and far field of seismic source (Brune, 1968; McGarr, 1991; Spottiswoode and McGarr, 1975). Typically the seismic source mechanism is not known in sufficient detail to validate the use of more complicated source models.

The model does not account for amplification of the peak particle velocity at the boundary of the excavation. The dynamic load and the condition of the rockmass are not known in sufficient detail to validate the use of amplification factor to adjust the boundary ppv at each drive node. Assuming that the relative amplification is constant at all drive locations, exclusion of amplification factor should not influence the models ability to predict the location of rockburst damage by the modelling approach.

The seismic source geometry and the radiation pattern for all events within the model are assumed spherical. In theory it is possible to account for any source shape using an appropriate geometric function. However in many cases, insufficient data is available to validate more complex models and a simple spherical source is assumed.

The model does not account for the peak ground motion and frequency characteristics of the coda waves that follow the peak ground motion pulse. Albrecht (2004) reviewed the characteristics of waveforms associated with rockbursts and large seismic events and found that the amplitude of the coda waves was significantly less than the peak ground motion component, suggesting that the peak ground motion is a reliable measure of the damaging component of ground motion contained within each seismic wave.

The ppv at the boundary of the excavation is derived from ground motion relationships calibrated to actual recordings of seismic events at mines. The ppv at the boundary of the excavation is a function of the following factors.

- The source location

- The seismic source parameters

- The seismic source radius

\section{The seismic source location}

The location of the seismic event is used to calculate the distance from the source of the event to the excavation. The distance is used to scale the amplitude of ground motion at the boundary of the excavation.

The location of the seismic source is generally output directly from the seismic system. For most modern seismic systems, the locations are automatically calculated, however the accuracy of the locations automatically calculated may be poor.

The accuracy of the seismic source location will depend on the spatial distribution of the sensor array relative to the event source, the adequacy of the assumed velocity model and the accuracy of the $\mathrm{P}$ and S-wave arrival picks. To check the accuracy of the calculated locations, it is important to manually reprocess the seismic event. Manual processing typically involves re-picking the $\mathrm{P}$-wave and $\mathrm{S}$-wave arrivals and deleting erroneous waveforms from the location calculation. 


\section{Seismic source parameters}

The event magnitude $\left(M_{\mathrm{L}}\right)$, seismic energy $\left(\mathrm{E}_{\mathrm{o}}\right)$, seismic moment $\left(\mathrm{M}_{\mathrm{o}}\right)$ and corner frequency $\left(\mathrm{f}_{\mathrm{c}}\right)$ of the seismic event are output directly from the seismic monitoring systems. These parameters are typically calculated automatically by the seismic systems, however as indicated in the source location discussion, all events should be manually processed to ensure accurate values.

Similar to the event location accuracy, the source parameters values are sensitive to the quality of the $P$ and $S$ wave arrival picks, the assumed velocity model and the sensor array coverage. To accurately calculate the source parameters, triaxial sensors are required. If no triaxial sensors are used in the source parameter calculations the event should not be used in the analysis.

\section{Source radius}

The source radius defines the boundary of the seismic source, which separates the near field from the far field. The source radius is quantified using the following two methods.

- Brune radius method

$$
r_{o}=\frac{K_{c} \beta_{o}}{2 \pi f_{c}}
$$

- Apparent volume method

$$
r_{A}=\sqrt[3]{\frac{3}{8 \pi} \frac{M o^{2}}{G E_{o}}}
$$

where

$\mathrm{r}_{0}$ is the seismic source radius (m),

$\mathrm{K}_{\mathrm{C}} \quad$ Brune's (1970) model assumes values of $\mathrm{K}_{\mathrm{C}}=1.97$ and $K_{C}=2.34$ for the $P$ and $S$ waves respectively,

$\beta_{0} \quad$ is the shear wave velocity $(\mathrm{m} / \mathrm{s})$,

$\mathrm{f}_{\mathrm{c}}$ is the corner frequency (hz),

$M_{o}$ is the seismic moment $(\mathrm{Nm})$,

$\mathrm{E}_{\mathrm{o}} \quad$ is the seismic energy $(\mathrm{J})$,

$\mathrm{G}$ is the shear modulus (GNm),

$\pi \quad$ is the universal constant pi approximately equal to 3.14.

The type of method is dependent on the failure mechanism at the seismic source. The ratio of the $S$ to $P$ wave energy is used to validate the use of the source radius expression. The Brune method (Equation 2) is based on a two-dimensional circular fault model and is suited to shear source mechanisms, characterised by dominant S-wave energy components. For events, characterised by dominant P-wave energies, the apparent volume method (Equation 3) may provide more realistic dimensions of non-shearing source mechanisms (Mendecki, 1997).

Empirical calibration of actual observations of rockburst damage can be used to select the most suitable model on a site-specific basis, assuming that the source of the event is coincident with the damage.

\section{PPV far field}

The ppv far field is quantified using a ppv-distance scaling relations derived from ground motion data recorded at sensor sites. Figure 2 shows the far field scaling relationships established using the source-sensor separation (R), peak particle velocity (PPV) and event magnitude (MAG) for the Big Bell and Junction mines respectively. The relationship established should define the upper limit of ppv's expected for each magnitude value.

If no far field ground motion recordings are available, the analytical expression proposed by McGarr (Equation 4) describing far field ground motion could be used. Albrecht (2004) showed that this expression was a reasonable indicator of the upper limit of far field ppv's recording by seismic system at three mine sites.

$$
\operatorname{ppv}_{\text {far field }}=0.57\left(\frac{r_{\mathrm{o}}}{\mathrm{R}}\right)\left(\frac{\Delta \sigma \mathrm{C}_{\mathrm{S}}}{\mathrm{G}}\right)
$$

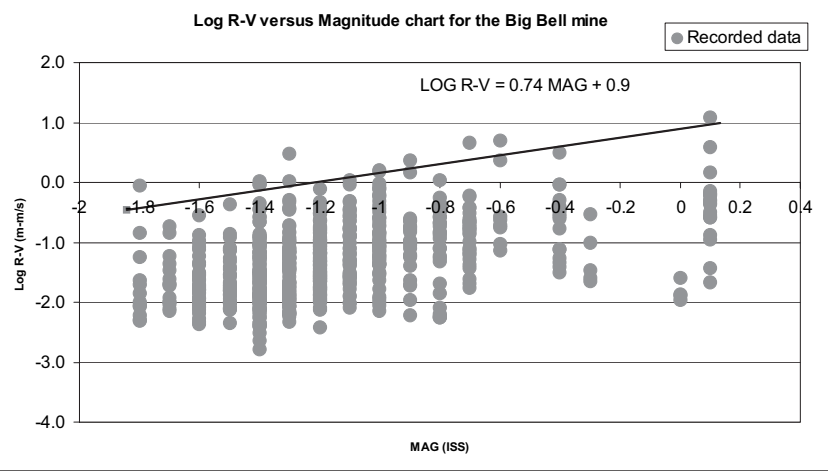

FIG. 2 Log R-V versus event magnitude relationship defining the upper limit of ppvs per magnitude recorded at a mine

\section{PPV near field}

The ppv near field describes the peak particle velocity within the source region of the seismic event. The ppv near field is calculated using the using the analytical expression developed by McGarr (Equation 5). This equation is similar to the far field ground motion expression; however the value of $R$ is assigned the value of the source radius $\left(\mathrm{r}_{0}\right)$.

$$
p p v_{\text {near field }}=0.57\left(\frac{\Delta \sigma C_{S}}{G}\right)
$$

$$
\begin{gathered}
\text { where } \\
\mathrm{C}_{\mathrm{S}} \text { is the shear wave velocity }(\mathrm{m} / \mathrm{s}), \\
\mathrm{G} \\
\Delta \sigma \quad \text { is the modulus of rigidity for the rockmass, }
\end{gathered}
$$

\subsubsection{Wavelength/span $(\lambda / D)$}

The ratio of the wavelength $(\lambda)$ of the dynamic load to the dimension of the excavation (D), influences the excavation loading rate and transmission characteristics of the incident seismic wave. This parameter is included in the analysis to assess if the $\lambda / D$ ratio influences the location of rockburst damage in mines. The dimension of the excavation (D) is approximated in the model using the excavation span, which is calculated using the Effective Radius Factor (ERF) proposed by Milne (1996).

The wavelength $(\lambda)$ is calculated using the Equation 6, where $f_{c}(H z)$ is the corner frequency and $C(m / s)$ is the Pwave or S-wave velocity of the incident seismic wave.

$$
\frac{\text { Wavelength }}{\text { Span }}=\frac{\lambda}{D}=\frac{C}{\mathrm{f}_{\mathrm{c}} \mathrm{D}}
$$

\subsection{The Condition of the Excavation}

The condition of the excavation boundary is described using the following list of parameters. These parameters were identified from literature as contributing to rockburst damage.

- Boundary stress state

- Yield state of the rockmass at the excavation boundary 
- Excavation geometry

- Drive orientation

- Local energy release density

- Rockmass fatigue

- Rockmass quality

- Support system capacity

\subsubsection{Boundary static stress state}

The MAP3d-SV boundary element program (Wiles, 2004a) is used to calculate the mining induced elastic static stress state around the boundary of the development drives. The model assumes linear elastic continuum rockmass behaviour, and therefore is best suited to linear and homogeneous materials (Brady and Brown, 1993). The boundary element method has the advantage over other numerical methods, due to its simplicity, ease of model construction, capability to model much larger problem sizes and the speed of calculation. The complexity and uncertainty of the rockmass at the boundary of the excavation negates any attempt to calculate the stress state with a higher degree of precision in the empirical model.

Stresses are calculated at points around the boundary of the excavation, using the development and stoping geometries at the time of rockbursting. The modelling technique does not evaluate the stress path preceding the rockburst damage, and therefore does not account for historic occurrences of yield or stress states less favourable than the modelled values. The elastic model assumes the stress state measured at the time of rockburst damage represents the worst case or most elevated yield state in the loading history. Consequently, the model may overestimate the stress state and strength of the rock material in cases where the rockmass has previously failed and subsequently unloaded. If the rock material appears to be highly damaged, this assumption may not be valid, requiring the use of non-linear elastic modelling to account for the yielding process.

Ideally, the stress values are calculated at regular interval around the full circumference of the excavation, to identify all boundary locations prone to failure. However to avoid excessive numerical modelling run times and unmanageable quantities of data, the stress state is sampled at a single location representative of rockburst damage. To validate the location of stress calculation, grid sections positioned through rockburst locations can be used to compare the boundary stress distribution relative to the locations of damage.

If separate areas of damage are observed around the boundary of the excavation, for example in the backs and walls, a stress value should be calculated at both locations.

The principal stress magnitudes and orientations are output from the MAP3D results file for each nodal position. Transformation of the stress tensor into the plane of major structures allows for the assessment of the shear and normal stress state.

\subsubsection{The yield state}

The yield state is defined as the ratio of the static stress to the strength of the rock material.

$$
\text { Yield state }=\frac{\text { Static stress }}{\text { Strength }}
$$

The yield state is an indicator of the load and displacement capacity of the rock material. A yield state exceeding unity indicates that the material has been loaded beyond its yield point and has plastically deformed. In zones of low confinement this may result in the weakening or reduction in load bearing capacity of the rock material, reducing the rock's failure resistance to transient seismic loads.
The strength of the rockmass is derived from a back analysis of boundary stress state at rockburst sites. Strength criteria are established using the principal stress components, the shear-normal stresses on critical structures and the unconfined compressive strength of the intact rock material. The following expressions define the three versions of yield state evaluated at each drive location in the model. If no critical structures are identified as influencing the locations of rockburst damage, the yield state describing shear failure is omitted from the analysis.

$$
\begin{gathered}
\mathrm{YS}\left(\sigma_{1}, \sigma_{3}\right)=\frac{\sigma_{1}}{\sigma_{1}^{\mathrm{f}}} \\
\mathrm{YS}\left(\tau, \sigma_{\mathrm{n}}\right)=\frac{\tau}{\tau^{\mathrm{f}}} \\
\mathrm{YS}(\mathrm{UCS})=\frac{\sigma_{1}}{\mathrm{UCS}}
\end{gathered}
$$

where;

- YS $\left(\sigma_{1} \sigma_{3}\right)$ is the yield state expressed as the ratio of the major principal stress to the rockmass strength defined using the major and minor principal stresses $\left(\sigma_{1}^{\mathrm{f}}\right)$,

- YS $\left(\tau, \sigma_{n}\right)$ is the yield state expressed as the ratio of the shear stress on the fault surface to the shear strength of discontinuity surface $\left(\tau^{\mathrm{f}}\right)$, and

- YS (UCS) is the yield state expressed as the ratio of the major principal stress to the unconfined compressive stress (UCS) of the intact rock material.

Multiple strength criteria may be required if the failure mechanism or the material properties and quality of the rockmass are distinctly different between rockburst damage sites.

\subsubsection{Excavation geometry}

The span of the excavation in plan is quantified at each node position using the Effective Radius Factor (ERF) proposed by Milne (1996). The ERF value is calculated from the average distance to points on the abutments, measured from the centre of the surface (Equation 11). The accuracy of the measurements is a function of the number of angular increments measured to the surface edge. Figure 3 illustrates the ERF measurement at the centre of a drive intersection. Preferably the ERF value is calculated from the surveyed drive outline, however the design can be used providing there are no substantial deviations.

An advantage of this factor is its ability to quantify irregular drive profiles, which conventional measurements of span, such as the hydraulic radius have difficulty (Milne et al., 1996). The ERF calculation is particularly well suited to the modelling approach, where the value is calculated at drive nodes positioned along the centreline of each drive segment.

$$
\mathrm{ERF}=\frac{0.5}{\frac{1}{\mathrm{n}} \sum_{\theta=1}^{\mathrm{n}} \frac{1}{\mathrm{r}_{\theta}}}
$$

where

$\mathrm{n}$ is the number of angle measurements,

$r_{\theta} \quad$ is the distance from the centroid to the excavation boundary $(\mathrm{m})$,

$\theta \quad$ is the angular increment.

The ERF factor is approximately half the excavation span of a development drive segment (Milne et al., 1996). 
If significant variations in the wall height are observed at a mine, the ERF technique can be applied to quantify the dimensions of the wall surface.

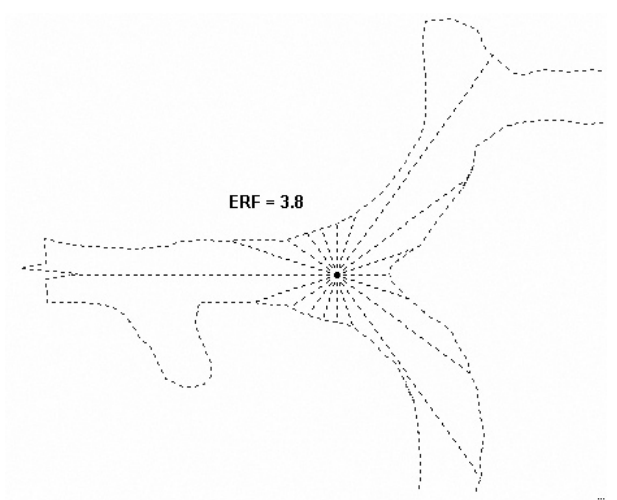

FIG. 3 The effective radius factor (after Milne et al., 1996)

\subsubsection{Drive orientation}

The Drive orientation is included in the model to evaluate its influence on the location of rockburst damage. Particular drive orientations may be less stable than others due to the orientation of the drive relative to the discontinuities or the stress field.

The orientation of the excavation surface is described in terms of the strike and dip of the excavation surfaces. The dip angle describes the line of maximum declination on the discontinuity or excavation surface, measured from the horizontal. The strike angle is perpendicular to the dip direction and is measured clock wise from true north. Figure 4 illustrates the dip and strike angle conventions used to describe the orientations of drive surfaces in the model.

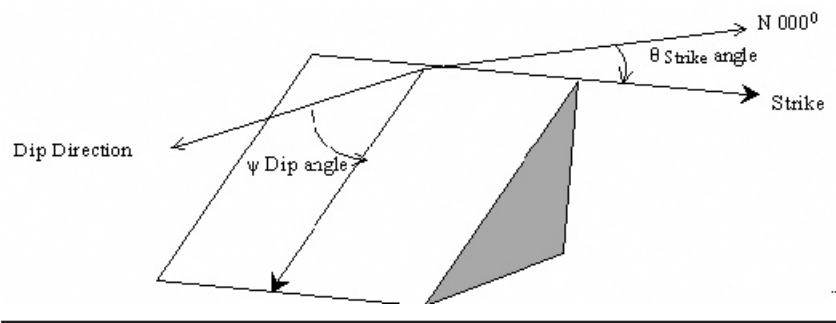

FIG. 4 Orientation convention used to describe the strike and drive orientations of the excavation surfaces (after Brady and Brown, 1993)

The excavation nodes (wall and back surfaces) are assigned the strike orientations of corresponding drive segments. Figure 5 illustrates the position of drive nodes contained for two drive segments with orientations $\theta_{1}$ and $\theta_{2}$.

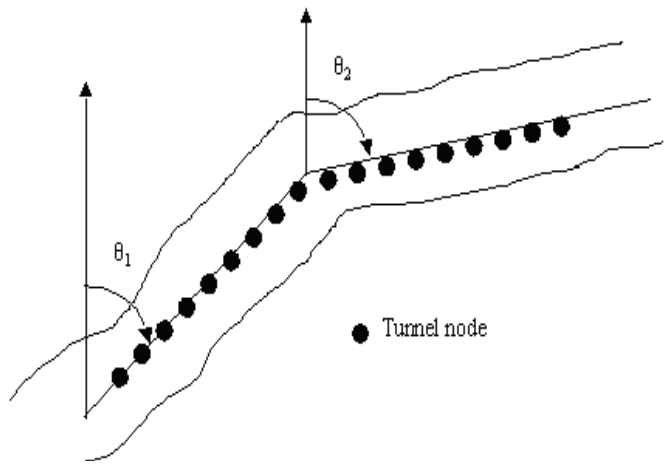

FIG. 5 Plan view of a drive level showing two drive segments (orientations $\theta_{1}$ and $\theta_{2}$ ) and the corresponding nodes
The drive orientation parameter at each node is quantified in terms of the strike orientation $(\Delta \theta)$ and dip orientation $(\Delta \phi)$ of the wall surfaces. If a particular orientation is identified as being susceptible to rockburst damage, the drive orientation parameters are expressed in terms of the minimum angle between the strike or dip orientation of the drive relative to the strike or dip of the critical orientation. The critical orientation may correspond to the orientation of a major structure or an unfavourable orientation relative to the mining induced stress field. Equations 12 and 13 define the expression used to calculate the strike and dip orientations of the excavations surfaces respectively.

$$
\begin{aligned}
& \Delta \theta=\left(\left|\theta_{\text {Critical }}-\theta_{\text {Drive }}\right|\right)_{\mathrm{MIN}} \\
& \Delta \varphi=\left(\left|\varphi_{\text {Crical }}-\varphi_{\text {Drive }}\right|\right)_{\mathrm{MIN}}
\end{aligned}
$$

where;

$\theta$ Critical is the strike of the critical orientation,

$\theta_{\text {Drive }}$ is the strike of the excavation surface,

$\phi_{\text {Critical }}$ is the dip of the critical orientation,

$\phi_{\text {Drive }}$ is the dip of the excavation surface.

For intersections, the most unfavourable drive orientation of the intersecting drives, in respect to the critical strike and dip orientations, is assigned to the intersection node.

\subsubsection{Rockmass fatigue (RF)}

Rockmass fatigue describes the degradation of the rockmass strength that occurs over the life of the excavation as a result of seismicity. In seismically active mines, the seismic event history in the vicinity around the excavation boundary may provide an indication of the amount of rockmass degradation that has occurred. The accuracy of the parameter will depend on the availability of a full seismic history for each excavation.

In the model, the rockmass fatigue parameter (RF) is quantified using the cumulative sum of seismic energy $\left(\mathrm{E}_{\mathrm{o}}\right)$. This parameter accounts for the total amount of seismic energy release at the boundary of an excavation prior to rockbursting. It is defined as the cumulative sum of energy release for seismic events whose source radius intersects the excavation node. The parameter does not quantify the influence of secondary loads from remote seismic events.

To account for the large range of recorded energies, the logarithmic of sum of the events for each node is taken (Equation 14). The log of the cumulative energy sum is truncated at 1 for events with values less than equal to 10 .

$$
\mathrm{RF}=\sum_{1}^{\mathrm{n}} \log \mathrm{E}_{\mathrm{o}}
$$

where;

- $\mathrm{n}$ is the number of events whose source radius intersect the excavation,

- $\mathrm{E}_{\mathrm{o}}$ is the seismic source energy of events intersecting the excavation.

\subsubsection{Local energy release density (LERD)}

An estimate of the elastic energy released $\left(W_{k}\right)$ on failure at the boundary of each development drive is conducted using the LERD calculation within the MAP3d numerical modelling program (Wiles, 2004b).

The LERD parameter is quantified at each node position, using test blocks positioned around the boundary of the 
excavation. The location of the test block should reflect the position of anticipated damage. In the case where damage is observed at multiple boundary positions, for example back and wall positions, the parameter should be evaluated separately. The size of the test block should represent the maximum volume of failure expected at the excavation boundary. Albrecht (2004) used $5.0 \mathrm{~m}$ cube test blocks positioned in the wall and back surfaces to model rockburst damaged resulting from MAG (ISS) 1.0 to 2.4 events.

\subsubsection{Rockmass quality}

In this paper the rockmass quality is characterised using the first quotient of the Rock Tunnelling Quality index Q developed by Barton et al. (1974). The other factors in the $Q$ expression are related to the strength of the discontinuities and the stress state. Both of these components are accounted for in model by the boundary stress state and yield state parameters.

This parameter is incorporated in the model to account for the distribution of discontinuities within the rockmass, which was observed to influence the stability of underground excavations (Potvin, 1988).

The $Q$ value defined in the model is denoted with an asterix to distinguish the parameter from the $Q$ value developed by Barton et al. (1974). Equation 15 defines the expression used to quantify the rockmass quality parameter $\left(Q^{*}\right)$ in the model.

$$
\mathrm{Q}^{*}=\frac{\mathrm{RQD}}{\mathrm{J}_{\mathrm{n}}}
$$

Where RQD is the Rock Quality Designation developed by Deere et al. (1967) to quantify joint spacing and $\mathrm{J}_{\mathrm{n}}$ is the joint set number.

\subsubsection{Support capacity}

The capacity of the support system installed at each drive node is quantified in terms of the energy and displacement capacities of the support system.

The energy capacity $(\mathrm{kJ} / \mathrm{m})$ of the support system per strike length of drive is derived from the cumulative sum of the energy capacities of each support element installed in a unit area of support. The unit area of support is calculated from the product of the bolt spacing and row spacing. It is assumed that all of the reinforcement elements are installed using the same pattern spacing. The following expression is used to calculate the energy capacity of the support system per unit area of support.

$$
\mathrm{SC}(\mathrm{kJ} / \mathrm{m})=\frac{\sum\left(\mathrm{e}_{1}+\mathrm{e}_{2}+\ldots\right)}{\mathrm{A}}
$$

where;

- $\mathrm{e}_{1}, \mathrm{e}_{2} \ldots$ are the energy capacities of each support element installed per unit area of support $(\mathrm{kJ})$,

- A is the unit area of support $\left(\mathrm{m}^{2}\right)$.

Table 1 shows the capacities of reinforcement elements and surface support. The technique used to quantify the support system capacity has attempted to account for the relative variations between capacities of the different systems used in mines. It is unlikely that a more complicated technique to quantify the support capacities of the integrated system would provide any more level of accuracy using the empirical modelling approach adopted in this paper.

Factors not accounted for in the model that influence the capacity of the support system, include bolt corrosion, incorrect pattern spacing and poor installation practice. For many mines, corrosion protection is provided through the use of galvanised or grouted elements. Alternatively the service life of the excavation is designed such that the corrosion does not influence the capacity of the support system. Assuming the support elements are installed as per design, exclusion of these factors from the support capacity calculation is not expected to significantly alter the relative capacities of support systems in the model. The influence of pre-existing static loads on support capacity is indirectly accounted in the model by the boundary stress state and yield state parameters.

\section{THE SIGNIFICANCE AND COMBINATION OF MODEL PARAMETERS}

This analysis identifies individual parameters that are useful in identifying the location of rockburst damage.

To identify significant parameters, the cumulative distributions of the rockbursting and non-rockbursting populations are compared. From these distributions, criteria are established for each parameter, which separate the rockburst and non-damaged populations.

Constraints are applied to the criteria selection process to ensure a sufficient number of rockburst damage sites are identified and that there is adequate separation between the two populations. An arbitrary constraint is applied in the model stipulating that the selected parameter criteria must predict at least $90 \%$ of the rockburst population and include no more than $75 \%$ of non-damaged sites.

If both criteria are satisfied, the optimum limit is defined as the point where there is maximum separation between the two populations. The separation between the two populations is evaluated in the analysis using the \% separation, which is quantified using the following expression.

$$
\% \text { Separation }=\% \mathrm{RB}-\% \mathrm{ND}
$$

where;

- \% RB is the percentage of rockburst nodes correctly predicted by the model criteria,

- \% ND is the percentage of non-damaged nodes wrongly predicted by the model criteria.

Figure 6 illustrates an example of the cumulative distributions of the rockburst and non-damaged populations, established for the ppv parameter at the excavation boundary. The optimal criterion is defined by the parameter value where there is maximum separation between the two populations and the criteria constraints are satisfied.

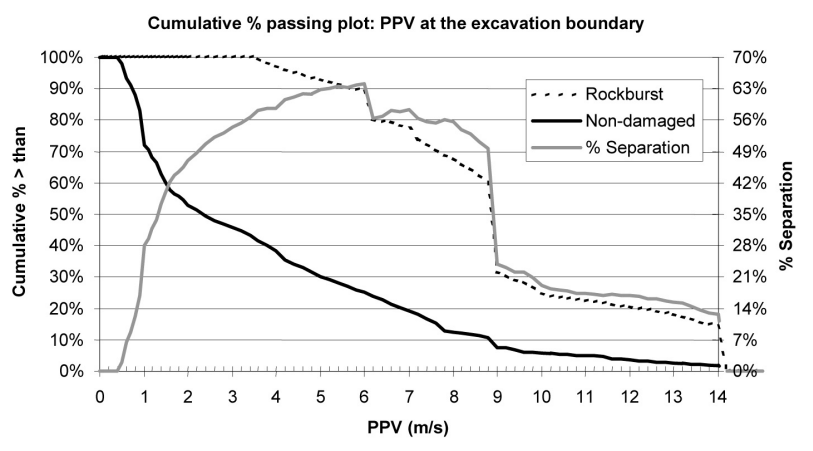

FIG. 6 Cumulative percent plot of the ppv parameter at the excavation boundary 
The significance of each individual model parameter is quantified in terms of the \% separation. The parameter with highest \%separation is the most significant.

Table 2 shows an example of the criteria and the \% separation for each parameter.

Combinations of the significant model parameters are also evaluated to improve the prediction accuracy of the model. The combination of parameters with the highest $\%$ separation is considered as the optimum model of rockburst damage. Figure 7 shows a combination of the SPAN and Yield state $\left(\sigma_{1}, \sigma_{3}\right)$ parameters defining locations of rockburst damage at a mine.

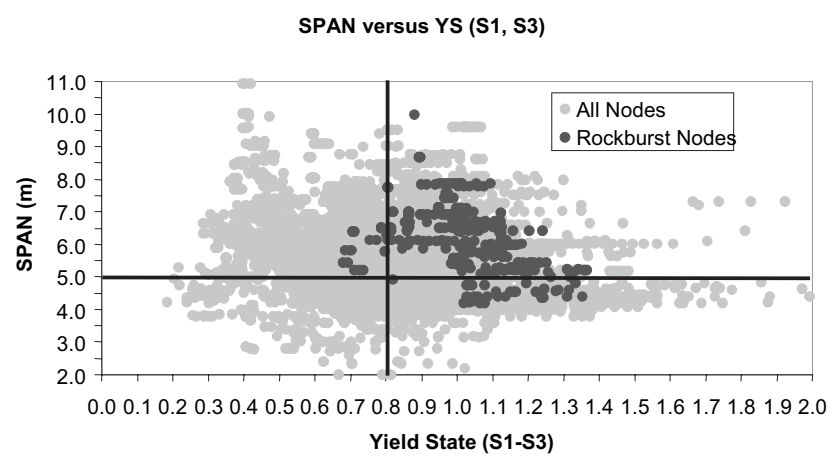

FIG. 7 Span versus YS $\left(\sigma_{1}, \sigma_{3}\right)$ plot defining rockburst damage at a mine

The usefulness of the model parameters and associated criteria are visualised by comparing the location of actual damage to model damage on a level plot. Figure 8 illustrates a comparison of model to actual damage on a level at a mine.

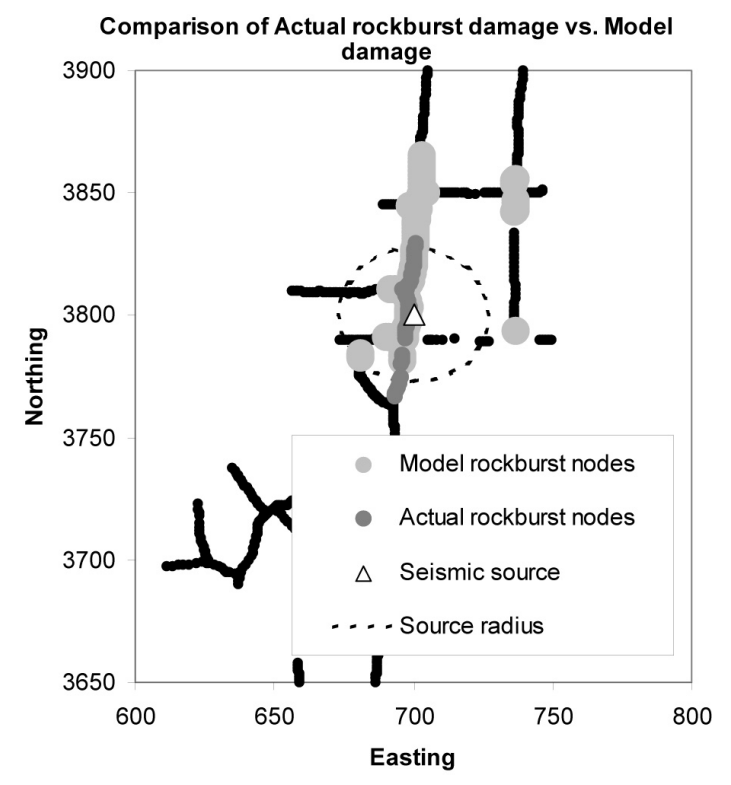

FIG. 8 Comparison of model damage versus actual damage

\section{APPLYING MODEL CRITERIA TO NON-DAMAGING SEISMIC EVENTS}

The model is applied to the population of non-damaging seismic events to test the accuracy of the empirical model criteria. If rockburst damage is predicted for an unacceptable number of events, the model should be reviewed.

\section{APPLICATION OF THE MODELLING APPROACH- BIG BELL MINE CASE STUDY}

This case study reviews the rockburst damage reported at the Big Bell mine between the $1^{\text {st }}$ of April 2000 and the $18^{\text {th }}$ of August 2002. The six most damaging rockbursts at the Big Bell mine have been reviewed in this case study. All of these events caused significant damage to the excavations, resulting in temporary drive closure and substantial rehabilitation to restore the functionality of the damaged excavations.

The model describes rockburst damage locations where the seismic event has induced either a substantial fall of ground, support failure or severe bulking of the excavation boundary.

The majority of rockbursts at the mine appear to be of similar mechanism, where a wedge is displaced from the backs of the drift, bounded by foliation and an intact shear fracture plane inclined to form a removable block. Buckling of the sidewalls was also observed which resulted in significant damage to the walls of the drifts.

Support failure was observed in all of the rockbursts. Typically support consisted of mesh, splits sets, and cables. In some cases, cone bolts were installed in the backs and walls.

The following model parameters where evaluated at the Big Bell mine.

The yield state, drive orientation, LERD and support capacity parameters are calculated at both the crown and sidewall positions to account for the occurrence of damage in both the backs and walls of the excavations. All other parameters used in the model are independent of the boundary position. The rockmass quality parameter $\left(Q^{*}\right)$ is not evaluated in the analysis, as it is considered uniform within the mining region of interest (Barrett, 2000). The Dip orientation parameter $(\Delta \phi)$ is also not considered due to the consistency in the dip of the excavation surfaces throughout the mine.

Table 3 shows parameter criteria and \% separation for each of the parameters evaluated at the mine for the back surface.

For the back surface, the ppv at the boundary of the excavation is the most significant parameter, which $91 \%$ of the rockburst populations and less than the $28 \%$ of the nondamaged populations having ppv's in excess of $5.4 \mathrm{~m} / \mathrm{s}$.

The combination of high shear stresses on the foliation, an elevated yield state $\left(\sigma_{1}, \sigma_{3}\right)$, the sub-parallel orientation of the drives relative to the foliation strike and larger spans, has contributed to the location of rockburst damage to the back surfaces at the Big Bell mine. The elevated values of LERD for the rockburst population for the back surface indicate the parameter may contribute to the location of damage.

The occurrence of elevated shear stresses and yield states $\left(\sigma_{1}, \sigma_{3}\right)$ at the back positions of rockburst damage sites are in agreement with the observations of damage observed at the damage sites, where a wedge is formed in the back surface from the intersection of a foliation and an intact shear fracture plane. It is proposed that the elevated yield state $\left(\sigma_{1}, \sigma_{3}\right)$ contributes to the formation of the intact shear fracture planes, which intersect the foliation forming removable block geometries. While the elevated shear stress destabilises the shear contact, prompting block removable.

Table 4 lists the \% separation for different combinations of model parameters for the back surface.

The significant parameters were combined to define the location of rockburst damage for the back and wall surfaces. For the back surface, the boundary ppv, drive orientation, the major principal stress $\left(\sigma_{1}\right)$ and the span parameters 
where combined. This combination of parameters delineated $87 \%$ of the rockburst node locations and less than $6 \%$ of non-damaged locations.

Figures 8 and 9 show locations of rockburst damage predicted by the model criteria compared actual locations of rockburst damage. The model criteria correctly predicted all locations of actual rockburst damage, while the locations wrongly predicted by the model criteria are adjacent the actual rockburst sites.

Application of the combined model criteria to the nondamaging seismic event population indicated the model was an accurate indicator of rockburst damage at the mine.

\section{SUMMARY AND CONCLUSIONS}

In this paper, a conceptual model is developed to quantify the rockburst damage potential of underground development drives submitted to seismic loads. Each of the model parameters is reviewed and techniques selected from literature to quantify the parameters at the boundary of excavations. The model is calibrated to actual observations of rockburst damage, with criteria established from a comparison of model parameters at damaged and non-damaged drive locations. The significance of individual parameters is ranked according to how well a criterion separates the damaged and non-damage populations. Combinations of parameters are also reviewed to improve the model prediction.

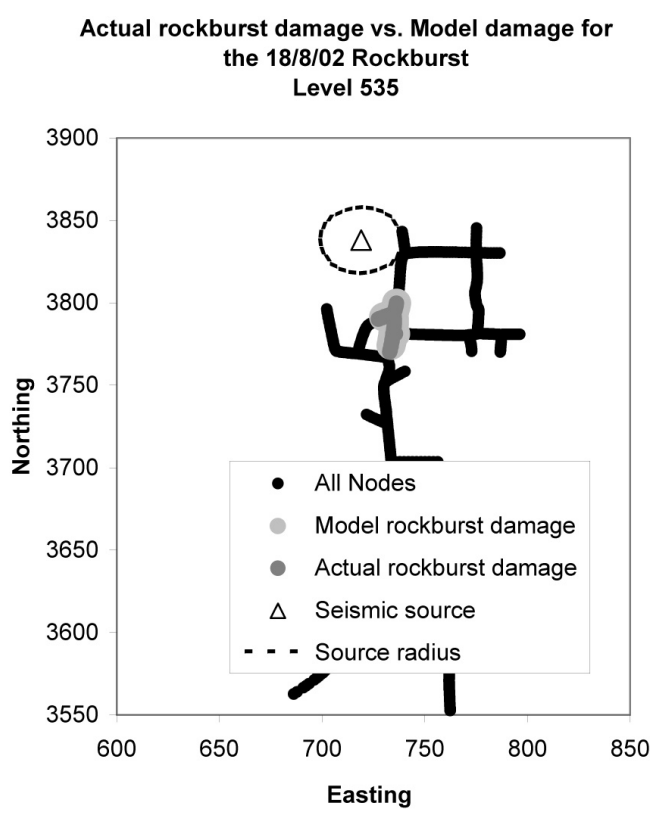

FIG. 9535 level plot of 18 August 2002 rockburst damage back damage criteria

TABLE 1 Capacity of reinforcement elements and surface support

\begin{tabular}{|c|c|c|c|c|}
\hline Parameter criteria & Load Capacity (kN) & Displacement Capacity (mm) & Energy Capacity & Reference \\
\hline Grouted rebar & 170 & 30 & $5 \mathrm{~kJ}$ & Kaiser et al., 1995 \\
\hline Split set & 100 & 200 & $20 \mathrm{~kJ}$ & Kaiser et al., 1995 \\
\hline Tubular grouted bolt (TGB) & 120 & 50 & $6 \mathrm{~kJ}$ & Kaiser et al., 1995 \\
\hline Cable bolt & 250 & 40 & $10 \mathrm{~kJ}$ & Kaiser et al., 1995 \\
\hline Cone bolt & 150 & 300 & $45 \mathrm{~kJ}$ & Kaiser et al., 1995 \\
\hline Mesh reinforced shotcrete & 70 & 150 & $10.5 \mathrm{~kJ} / \mathrm{m}$ & Kaiser et al., 1995 \\
\hline Fibre reinforced shotcrete & 70 & 150 & $10.5 \mathrm{~kJ} / \mathrm{m}$ & Stacey et al., 2002 \\
\hline
\end{tabular}

TABLE 2 Example of model criteria, \% separation and model prediction accuracy for parameters

\begin{tabular}{|c|c|c|c|}
\hline Parameter criteria & $\begin{array}{l}\% \text { of rockburst nodes correctly } \\
\text { predicted by model criteria }\end{array}$ & $\begin{array}{l}\% \text { of non-damaged nodes wrongly } \\
\text { predicted by model criteria }\end{array}$ & $\%$ Separation \\
\hline $\operatorname{PPV}(\mathrm{m} / \mathrm{s})>\mathrm{x}_{1}$ & $100 \%$ & $50 \%$ & $50 \%$ \\
\hline $\operatorname{SPAN}(m)>x_{2}$ & $100 \%$ & $65 \%$ & $35 \%$ \\
\hline $\operatorname{LERD}\left(\mathrm{MJ} / \mathrm{m}^{3}\right)>\mathrm{x}_{3}$ & $95 \%$ & $62 \%$ & $33 \%$ \\
\hline $\mathrm{YS}\left(\sigma_{1}, \sigma_{3}\right)>\mathrm{x}_{4}$ & $93 \%$ & $70 \%$ & $23 \%$ \\
\hline
\end{tabular}


TABLE 3 The significance of model parameters used to define rockburst damage in the back surface of excavations at the Big Bell mine

\begin{tabular}{|c|c|c|c|c|}
\hline Model Parameter & $\begin{array}{l}\text { Criteria defining } \\
\text { rockburst damage }\end{array}$ & $\begin{array}{c}\% \text { of Rockburst nodes correctly } \\
\text { predicted by criteria }\end{array}$ & $\begin{array}{l}\% \text { of Non damaged nodes } \\
\text { wrongly predicted by criteria }\end{array}$ & \% Separation \\
\hline $\mathrm{PPV}(\mathrm{m} / \mathrm{s})$ & $>5.4$ & $91 \%$ & $28 \%$ & $63 \%$ \\
\hline$\Delta \theta$ & $<7.2^{\circ}$ & $98 \%$ & $52 \%$ & $46 \%$ \\
\hline$\tau(\mathrm{MPa})$ & $>38$ & $91 \%$ & $49 \%$ & $41 \%$ \\
\hline$Y S\left(\sigma_{1}, \sigma_{3}\right)$ & $>0.80$ & $94 \%$ & $53 \%$ & $41 \%$ \\
\hline$\sigma_{1}(\mathrm{MPa})$ & $>100$ & $98 \%$ & $60 \%$ & $38 \%$ \\
\hline LERD $\left(\mathrm{MJ} / \mathrm{m}^{3}\right)$ & $>0.14$ & $93 \%$ & $59 \%$ & $34 \%$ \\
\hline$\sigma_{\mathrm{n}}(\mathrm{MPa})$ & $>82$ & $90 \%$ & $57 \%$ & $33 \%$ \\
\hline YS (UCS) & $>0.55$ & $98 \%$ & $65 \%$ & $33 \%$ \\
\hline SPAN (m) & $>4.90$ & $90 \%$ & $59 \%$ & $31 \%$ \\
\hline$\lambda / D$ & $<20$ & $97 \%$ & $72 \%$ & $25 \%$ \\
\hline$\sigma_{3}(\mathrm{MPa})$ & $<20$ & $93 \%$ & $78 \%$ & $16 \%$ \\
\hline YS $\left(\tau, \sigma_{n}\right)$ & $>0.65$ & $90 \%$ & $76 \%$ & $14 \%$ \\
\hline $\mathrm{SC}\left(\mathbf{k J} / \mathrm{m}^{2}\right)$ & $>27$ & $100 \%$ & $88 \%$ & $12 \%$ \\
\hline RF (kJ) & $<2100$ & $99 \%$ & $88 \%$ & $11 \%$ \\
\hline
\end{tabular}

TABLE 4 Model prediction accuracy (MPA) for combinations of model parameters used to predict rockburst damage in the back surface of excavations at the Big Bell mine

\begin{tabular}{|c|c|c|c|}
\hline Parameter combinations & $\begin{array}{l}\% \text { of Rockburst nodes correctly } \\
\text { predicted by criteria }\end{array}$ & $\begin{array}{l}\% \text { of Non damaged nodes } \\
\text { wrongly predicted by criteria }\end{array}$ & $\begin{array}{l}\text { Model prediction } \\
\text { accuracy }(\%)\end{array}$ \\
\hline $\mathrm{PPV}+\Delta \theta+\mathrm{SPAN}+\sigma_{1}$ & $87 \%$ & $6 \%$ & $81 \%$ \\
\hline $\mathrm{PPV}+\Delta \theta$ & $98 \%$ & $18 \%$ & $80 \%$ \\
\hline $\mathrm{PPV}+\Delta \theta+\sigma_{1}$ & $95 \%$ & $16 \%$ & $79 \%$ \\
\hline $\mathrm{PPV}+\Delta \theta+\mathrm{YS}\left(\sigma_{1}, \sigma_{3}\right)+\mathrm{SPAN}$ & $83 \%$ & $6 \%$ & $77 \%$ \\
\hline $\mathrm{PPV}+\Delta \theta+\mathrm{YS}\left(\sigma_{1}, \sigma_{3}\right)$ & $92 \%$ & $15 \%$ & $77 \%$ \\
\hline $\mathrm{PPV}+\sigma_{1}$ & $97 \%$ & $21 \%$ & $76 \%$ \\
\hline $\mathrm{PPV}+\Delta \theta+\tau$ & $88 \%$ & $14 \%$ & $74 \%$ \\
\hline $\mathrm{PPV}+\Delta \theta+\tau+\mathrm{YS}$ (UCS) & $87 \%$ & $14 \%$ & $73 \%$ \\
\hline $\mathrm{PPV}+\Delta \theta+\tau+\mathrm{SPAN}$ & $78 \%$ & $6 \%$ & $72 \%$ \\
\hline $\mathrm{PPV}+\Delta \theta+\tau+\mathrm{YS}(\mathrm{UCS})+\mathrm{SPAN}$ & $78 \%$ & $6 \%$ & $72 \%$ \\
\hline $\mathrm{PPV}+\Delta \theta+\tau+\mathrm{YS}\left(\sigma_{1}, \sigma_{3}\right)$ & $84 \%$ & $13 \%$ & $71 \%$ \\
\hline PPV + SPAN & $90 \%$ & $20 \%$ & $70 \%$ \\
\hline $\mathrm{PPV}+\mathrm{YS}\left(\sigma_{1}, \sigma_{3}\right)$ & $94 \%$ & $25 \%$ & $69 \%$ \\
\hline $\mathrm{PPV}+\lambda / \mathrm{D}$ & $97 \%$ & $32 \%$ & $65 \%$ \\
\hline $\mathrm{PPV}+\tau$ & $89 \%$ & $25 \%$ & $64 \%$ \\
\hline $\mathrm{PPV}+\Delta \theta+\tau+\mathrm{YS}\left(\sigma_{1}, \sigma_{3}\right)+$ LERD & $75 \%$ & $13 \%$ & $62 \%$ \\
\hline $\mathrm{PPV}+\Delta \theta+\tau+\mathrm{YS}(\mathrm{UCS})+$ LERD & $75 \%$ & $13 \%$ & $62 \%$ \\
\hline $\mathrm{PPV}+\Delta \theta+\mathrm{YS}(\mathrm{UCS})+$ LERD & $76 \%$ & $14 \%$ & $62 \%$ \\
\hline $\mathrm{PPV}+\tau+\mathrm{YS}\left(\sigma_{1}, \sigma_{3}\right)$ & $85 \%$ & $23 \%$ & $62 \%$ \\
\hline $\mathrm{PPV}+\Delta \theta+$ LERD & $77 \%$ & $16 \%$ & $61 \%$ \\
\hline $\mathrm{PPV}+\Delta \theta+\mathrm{SPAN}$ & $67 \%$ & $13 \%$ & $54 \%$ \\
\hline PPV + LERD & $77 \%$ & $28 \%$ & $49 \%$ \\
\hline
\end{tabular}

\section{ACKNOWLEDGMENT}

The access to information and generous help provided by the geotechnical staff at Harmony Gold Big Bell mine, Kalgoorlie Consolidated Gold Mines Mt Charlotte mine and Gold Fields Australia Junction mine is gratefully acknowledged. Also much appreciated is the support of the Australian Centre for Geomechanics, and the Mine Seismicity and Rockburst Risk Management project sponsors; namely:

- Barrick Gold of Australia,

- Gold Fields Australia,

- Harmony Gold Australia,

- Kalgoorlie Consolidated Gold Mines,

- Minerals and Energy Research Institute of Western Australia,

- Sons of Gwalia Limited, and

- WMC Resources Limited. 


\section{REFERENCES}

Albrecht, J.A. (2004) Quantifying damage potential for underground development subjected to seismic loading. PhD thesis in preparation. University of Western Australia.

Barrett, D. (2000) Big Bell, Underground again and going deeper. In Mining in high stress and seismically active conditions. Edited by ACG. Perth ACG, Sect 16, pp. 11-20.

Barton, N., Lien, R., and Lunde, J. (1974) Engineering classification of rockmasses for the design of tunnel support. Rock mech., 10(1-2): pp. 189-239.

Bieniawski, Z.T. (1989) Engineering rockmass classifications. Wiley, New York.

Brady, B.H.G. and Brown, E.T. (1993) Rock mechanics for underground mining. Chapman and Hall.

Brune, J.N. (1968) Seismic moment, seismicity, and rate of slip along major fault zones. Journal of Geophysical research, 73(2): pp. 777-784.

Butler, A.G. and van Aswegen, G. (1993) Ground velocity relationships based on a large sample of underground measurements in burst-prone mines. In Proc. 3rd Int. Symp. Rockbursts and seismicity in mines. Balkema, pp. 41-48.

Deere, D.U., Hendron, A.J., Patton, F.D. and Cording, E.J. (1967) Design of surface and near surface construction in rock. In Failure and breakage of rock - Proc. 8th U.S. Symp. Rock Mech. Edited by C. Fairhurst. New York, pp. 237-302.

Dowding, C.H. and Rozen, A. (1978) Damage to rock tunnels from earthquake loading. J. Geotech. Eng. Div. ASCE, 104: pp. 175-191.

Gill, D.E., Aubertin, M. and Simon, R. (1993) A practical approach to the evaluation of rockburst potential. In Rockbursts and seismicity in mines. Edited by R.P. Young. Balkema, pp. 63-68.

Grimstad, E. and Barton, N. (1993) Updating the Q-system for NMT. In Int. Symp. on sprayed concrete - modern use of wet mix sprayed concrete for underground support. Norwegian Concrete Association, Norway, pp. 46-66.

Hedley, D.G.F. (1992) Rockburts handbook for Ontario hardrock mines. CANMET, Ottawa.

Hoek, E., Kaiser, P.K. and Bawden, W.F. (1995) Support of underground excavations in hard rock. Balkema, Rotterdam.

Kaiser, P.K., McCreath, D.R. and Tannant, D.D. (1995) Rockburst support handbook review draft. Geomechanics Research Centre, Laurentian University.

Kaiser, P.K., Tannant, D.D., McCreath, D.R. and Jesenak, P. (1992) Rockburst damage assessment procedure. In Rock suport in mining and underground construction. Edited by P.K. Kaiser and D.R. McCreath Balkema, pp. 639-647.

Laubscher, D.H. (1977) Geomechanics classification of jointed rockmasses - mining applications. In Trans. Inst. Min. Metall., Vol.86, pp. A1-8.

McGarr, A. (1991) Observations Constraining Near Source Ground Motion Estimated From Locally Recorded Seismograms. Journal of Geophysical Research, 96: pp. 16495-16508.

McGarr, A., Green, R.W.E. and Spottiswoode, S.M. (1981) Strong ground motion of mine tremors: some implications for near source ground motion parameters. Bulletin of the seismological society of America, 71(1): pp. 295-319.

Mendecki, A.J. (1997) Seismic monitoring in mines. Chapman and Hall, London.

Milne, D., Pakalnis, R.C. and Felderer, M. (1996) Surface geometry assessment for open stope design. Rock mech. Tools and Techniques, 1: pp. 315.

Potvin, Y. (1988) Empirical open stope design in Canada, University of British Columbia.

Spottiswoode, S.M. (1984) Source mechanisms of mine tremors at Blyvooruitzicht Gold mine. In 1st Int. Congress on Rockburst and seismicity in mines. Johannesburg, pp. 29-37.

Spottiswoode, S.M. and McGarr, A (1975) Source Parameters of tremors in deep level gold mine. Bulletin of the seismological society of America, 65(1): pp. 93-112.

St John, C.M. and Zahrah, T.F. (1987) A seismic design of underground structures. Tunnelling and underground space technology, 2(2): pp. 165-197.

Stacey, T.R. and Ortlepp, W.D. (2000) Support appropriate for dynamic loading and large static loading in block cave mining openings. In MassMin 2000. Brisbane, pp. 783-789.

Wiles, T. (2004a) Map3D users manual - Version 50.

Wiles, T. (2004b) Energy release rate/Loading system stiffness/Non-linear modelling. In Map 3D course notes. Mine Modelling Pty Ltd. 